\title{
Economic Factors and Physical Properties of Finger Joint Timber Product to Promote Effective Utilization of Natural Resources
}

\author{
Abeysinghe L.S. ${ }^{*}$, Pathirana S. ${ }^{1}$ and Kumara M. ${ }^{2}$ \\ ${ }^{I}$ Department of Agricultural Economics and Extension, University of Ruhuna, Sri Lanka \\ ${ }^{2}$ State Timber Cooperation, Sri Lanka \\ *sandika@agecon.ruh.ac.lk
}

\begin{abstract}
Finger joint (FJ) is one of the most sustainable, eco-friendly and economically valuable concept. It ensures the sustainable utilization of small wood cut pieces which removed as waste. Wood pieces are jointed together using glued box comb finger joint cut. It is a new concept for Sri Lankan furniture industry. Therefore, it is necessary to analyze about economic parameters and physical properties of FJ product to ensure the sustainable utilization of FJ timber products. This study attempted to compare strength, appearance and economic variables such as prices, cost of production and profit of FJ products. Comparison of FJ product (Model: STC B-FJ 0019) with the similar size normal timber products (Model:STC B-132) was done to achieve the objective of the study. Three point bending test was done to evaluate Modulus of Elasticity, Modulus of Rupture and maximum force by using UTM. Timber cooperation laboratory was utilized to evaluate strength properties. According to the results of the statistical analysis, strength reduction for FJ products was significantly high. Strength also varied with timber species. Eucalyptus grandis and Pinus showed the highest strength properties while Teak showed the lowst value. MOE values did not show significant difference $(0.224)$ between Jak, Kumbuk, Teak, Mahogany, Pinus, and E. grandis. Strength on vertical and horizontal FJ cuts did not show significant differences although vertical cut was slightly higher. Timber cost for FJ product showed the lowest because of small cut pieces but finishing material, labour, machinery and factory overheads costs were higher than common furniture. Unit production cost for FJ was Rs.171.91 which is higher compared to the cost of normal furniture of Rs. 147.88. FJ furniture showed the higher price most of the time. Therefore, profitability of FJ furniture was significantly higher than common furniture. The uniqueness and high demand help to increase market price and gain more income for producers. On this context FJ product can be promoted to ensure sustainable utilization of timber. Further, this subject is open for further researchers.
\end{abstract}

Keywords: Finger joint, Strength properties, Satisfaction

Proceedings of the International Forestry and Environment Symposium 2016, Department of Forestry and Environmental Science, University of Sri Jayewardenepura, Sri Lanka. 